\title{
Penerapan Sunnah Rosul Sebelum Tidur Meningkatkan Kualitas Tidur Pasien Kanker Payudara
}

\author{
Implementation of the Prophet's Sunnah Before Sleeping to Improve Sleep Quality of Breast \\ Cancer Patients
}

\author{
Diyanah Syolihan Rinjani Putri ${ }^{1 *}$, Sri Nabawiyati Nurul Makiyah ${ }^{1}$, Dewi Puspita ${ }^{1}$ \\ ${ }^{1}$ Universitas Muhammadiyah Yogyakarta
}

DATA NASKAH:

Received:2 Jul 2018

Reviewed: 5 Jul 2018

Revised: 13 Jul 2018

Accepted: 14 Jul 2018

\section{*KORESPONDENSI:}

putridiana186@gmail.com

DOI:

$10.18196 / \mathrm{mm} .180217$

TYPE OF ARTICLE:

Research

\begin{abstract}
Abstrak: Pasien kanker payudara mendapatkan penatalaksanaan kemoterapi. Salah satu efek kemoterapi adalah kualitas tidur buruk. Seseorang yang mengalami gangguan tidur bisa mengakibatkan kelelahan, depresi dan kecemasan. Penerapan sunnah Rosul sebelum tidur mempunyai efek positif bagi tubuh. Penelitian ini bertujuan untuk meningkatkan kualitas tidur pasien kanker payudara yang menjalani kemoterapi dengan penerapan sunnah Rosul sebelum tidur. Penelitian ini menggunakan Quasi experiment pretest-postest with intervention control group design. Sampel sebanyak 26 responden kanker payudara dengan teknik Purposive Sampling. Kriteria inklusi yaitu pasien yang menjalani kemoterapi 1 minggu sekali, mempunyai kualitas tidur buruk, beragama islam, medapatkan kemoterapi adjuvan dan kriteria eksklusinya mempunyai alergi/sensitifitas terhadap suara. Penilaian kualitas tidur menggunakan Pittsburgh Sleep Quality Index. Intervensi yang diberikan penerapan sunnah Rosul sebelum tidur selama 7 hari. Data kualitas tidur dianalisis menggunakan Independent t-test. Kualitas tidur kelompok kontrol pretest 9,83 dan posttest 11,83, kualitas tidur kelompok intervensi pretest 12,93 dan posttest 7,00. Hasil posttest pada kedua kelompok dengan $p$ value $=0,003$ menunjukkan terdapat pengaruh penerapan sunnah Rosul sebelum tidur. Penerapan sunnah Rosul sebelum tidur efektif untuk meningkatkan kualitas tidur pasien kanker payudara yang menjalani kemoterapi.
\end{abstract}

Kata kunci: Kanker Payudara; Kemoterapi; Sunnah Rosul; Kualitas Tidur

Abstract: Most breast cancer patients are suggested to under of chemotherapy. One of the effects of chemotherapy is bad sleep. Someone suffering from sleep disorders is potential to suffer from fatigue, depression, and anxiety. The Implementation of the Prophet's sunnah before sleeping gives the body a positive effect. The research aims to improve sleep quality of breast cancer patients undergoing chemotherapy with implementation of the Prophet's sunnah before sleeping. The research applied the Quasi Experiment pretest-posttest with intervention and control group design. The collected samples are 26 breast cancer respondents with Purposive Sampling technique. The inclusion criteria are patients undergoing chemotherapy one week, have poor sleep quality, Moslem, obtain adjuvant chemotherapy and Exclusion criteria have allergies / sensitivities to noise. Sleep quality was assessed by using the Pittsburg Sleep Quality Index. The intervention of the Prophet's sunnah was done before sleeping for 7 days. Sleep quality data were analyzed by using the Independent t-test. Sleep quality controls group pretest 9.83 and posttest 11.83, sleep quality interventions group pretest 12,93 and posttest 7,00 . The posttest results of the two groups with $p$ value $=0.003$, shows there is an effect of applying the sunnah of the Prophet before sleeping. The implementation of the Prophet's sunnah before sleeping was effective to improve sleep quality of breast cancer patients undergoing of chemotherapy. 
Key words: Breast Cancer; Chemotherapy; Prophet's Sunnah; Sleep Quality

\section{PENDAHULUAN}

Menurut American Cancer Society (ACS), terdapat kasus baru 63.410 kanker payudara. ${ }^{1}$ Penatalaksanaan yang paling sering dilakukan oleh pasien kanker payudara yaitu kemoterapi. Pengobatan dengan kemoterapi merupakan suatu terapi yang melelahkan dan mempunyai banyak efek samping yang dialami penderita kanker payudara. ${ }^{2}$ Efek samping kemoterapi antara lain kelelahan, rambut rontok, anoreksia, insomnia atau gangguan tidur bahkan menyebabkan timbulnya emosi yang negatif seperti terjadinya kecemasan dan depresi. ${ }^{3}$

Gangguan tidur dapat mempengaruhi kualitas tidur pada pasien kanker payudara yang menjalani kemoterapi sebanyak 63,3\% dari 823 pasien mengalami gangguan tidur setelah kemotearpi. ${ }^{4}$ Tian et al. (2015), ${ }^{5}$ menyatakan pasien kanker sebelum mendapatkan terapi mengalami gangguan tidur $52,6 \%$ setelah mendapatkan terapi meningkat menjadi $64,5 \%$.

Seseorang yang telah menjalani kemoterapi mengalami waktu yang lama untuk memulai tidur dan sering terbangun tengah malam dari 21 kali menjadi 29 kali. $^{6}$ Gangguan tidur bisa mengakibatkan kelelahan, depresi, kecemasan yang lebih besar, mudah tersinggung, sensitivitas nyeri, tremor otot, imunosupresi dan kurang kewaspadaan siang hari. $^{7}$

Penatalaksanaan gangguan tidur sangat penting untuk dilakukan salah satunya dengan cara terapi nonfarmakologi yang efektif dan aman untuk meningkatkan kualitas tidur yaitu Complementary and Alternative Medicine (CAM) pada bagian MindBodt Therapy yaitu berdoa. 8 Pada ajaran agama Islam terdapat Sunnah Rosul yang dikerjakan sebelum tidur yang di dalamnya terdapat kegiatan yang dilakukan sebelum tidur dan berdoa. ${ }^{9}$

Hasil penelusuran literatur, penelitian terkait penatalaksanaan gangguan tidur pada pasien kanker payudara yang menjalani kemoterapi menggunakan terapi musik sudah ada, akan tetapi belum ditemukan penatalaksanaan menggunakan pendekatan Mind-Body Therapy yaitu penerapan sunnah Rosul sebelum tidur.

Penelitian ini bertujuan untuk meningkatkan kualitas tidur pasien kanker payudara yang menjalani kemoterapi dengan penerapan sunnah Rosul sebelum tidur.

\section{BAHAN DAN CARA}

Penelitian ini menggunakan Quasi eksperiment dengan pretest-posttest with intervention control group design. Populasi dalam penelitian adalah seluruh pasien kanker payudara yang menjalani kemoterapi di Rumah Sakit Umum Daerah (RSUD) Temenggung sebanyak 56 orang. Pemilihan sampel dalam penelitian ini menggunakan Purposive Sampling.

Kriteria inkulusi pada penelitian ini adalah responden kanker payudara tidak mengalami gangguan pendengaran, bisa membaca dan menulis, beragama islam, usia >18 tahun, menjalani kemoterapi 1 minggu sekali, mendapatkan kemoterapi adjuvan (kemoterapi setelah mendapatkan operasi radikal), berjenis kelamin perempuan yang sedang menjalani kemoterapi, mempunyai kualitas tidur buruk, terdapat keluarga yang tinggal dalam satu rumah dengan responden.

Kriteria eksklusi yaitu responden tidak mengikuti penelitian sampai akhir, mempunyai alergi/sensitifitas terhadap suara seperti epilepsi. Jumlah responden yang memenuhi kriteria inklusi dan eksklusi sebanyak 26 orang yang terdiri dari 12 responden kelompok kontrol dan 14 responden kelompok intervensi. Penelitian ini dilakukan pada tanggal 28 Mei-12 Juni 2018 di ruang kemoterapi RSUD Temanggung.

Instrumen pertama yang digunakan yaitu kuesioner Pittsburgh Sleep Quality Index (PSQI) untuk menilai kualitas tidur. Penilaian PSQI diberikan nilai 0-21. Kualitas tidur dikatakan baik bila $\leq 5$ dan dikatakan kualitas tidur buruk $>5 .{ }^{10}$ Instrumen kedua yaitu menggunakan Instrumen lantunan murottal Al-Qur'an dengan nilai kalibrasi $65-80 \mathrm{Db}$ disimpan di MP3 player.

Inervensi penerapan sunnah Rosul sebelum tidur diberikan pada kelompok intervensi berupa kegiatan sebelum tidur terdiri dari mencuci tangan dengan sabun, menyikat gigi, berwudhu masingmasing 1 kali, membersihkan tempat tidur sambil membaca membaca Basmallah sebanyak 3 kali.

Kegiatan berikutnya duduk di samping tempat tidur membaca Basmallah dilanjutkan mendengarkan murottal Al-Qur'an surat Al-Ihlas, Al-Falaq, AnNas dan ayat kursi masing-masing 3 kali putaran selama 8 menit 50 detik. Setelah selesai mendengarkan Murottal Al-Qur'an meniupkan ke tangan kemudian diusapakan ke seruruh tubuh sebanyak 3 kali kemudian membaca Alhamdulillah. 
Kegiatan selanjutnya melakukkan dzikir yang terdiri dari Subhanallah, Alhamdulillah, Allahu Akbar masing-masing sebayak 33 kali dengan menggunakan tasbih. Selanjutnya mengatur posisi tidur miring kanan, membaca do'a sebelum tidur, melapaskan Astaghfirullaahal'azihiimi sampai dengan tertidur.

Intervensi penerapan sunnah Rosul sebelum tidur dilakukkan 30 menit menjelang tidur biasa masing-masing responden, dilakukan secara mandiri di rumah masing-masing. Peneliti mengingatkan melalui SMS/Telepon/WhatsApp. Pengontrolan dilakukan dengan kunjungan rumah dan pertemuan di Poli Onkologi saat kontrol.

Analisis data yang digunakan untuk menilai pengaruh pemberian penerapan sunnah Rosul sebelum tidur pada pasien kanker payudara yang menjalani kemoterapi menggunakan Independen t-test.

\section{HASIL}

Karakteristik subjek penelitian pasien kanker payudara yang menjalani kemoterapi terdiri dari tingkat pendidikan, lama kemoterapi, penggunaan lampu saat tidur, frekuensi kemoterapi dan usia dapat dilihat pada Tabel 1.

Berdasarkan Tabel 1. responden pada kelompok kontrol maupun intervensi mayoritas pendidikannya adalah SD sebanyak 35,7\% pada kelompok

Tabel 1. Karakteristik Responden Kanker Payudara yang Menjalani Kemoterapi di RSUD Temanggung $(\mathrm{n}=26)$

\begin{tabular}{|c|c|c|c|c|}
\hline \multirow{3}{*}{ Karakteristik } & \multicolumn{4}{|c|}{ Kelompok } \\
\hline & \multicolumn{2}{|c|}{$\begin{array}{c}\text { Intervensi } \\
(n=14)\end{array}$} & \multicolumn{2}{|c|}{$\begin{array}{c}\text { Kontrol } \\
(n=12)\end{array}$} \\
\hline & $\mathrm{n}$ & $(\%)$ & $\mathrm{N}$ & $(\%)$ \\
\hline \multicolumn{5}{|l|}{ Tingkat pendidikan } \\
\hline Tidak sekolah & - & - & 1 & 8,3 \\
\hline $\mathrm{SD}$ & 5 & 35,7 & 6 & 50 \\
\hline SMP & 4 & 28,6 & 3 & 25 \\
\hline SMA & 2 & 14,3 & 2 & 16,7 \\
\hline Perguruan tinggi & 3 & 21,4 & - & - \\
\hline \multicolumn{5}{|l|}{ Lama kemoterapi } \\
\hline$<1$ tahun & 13 & 92,9 & 12 & 100 \\
\hline 1-3 tahun & 1 & 7,1 & - & - \\
\hline \multicolumn{5}{|c|}{ Penggunaan lampu saat tidur } \\
\hline Ya & 8 & 57,1 & 9 & 75 \\
\hline Tidak & 6 & 42,9 & 3 & 25 \\
\hline \multirow[t]{2}{*}{ Karakteristik } & \multicolumn{4}{|c|}{$\mathrm{X} \pm \mathrm{SD}$} \\
\hline & \multicolumn{2}{|c|}{ Kontrol } & \multicolumn{2}{|c|}{ Intervensi } \\
\hline Usia & \multicolumn{2}{|c|}{$49,17(7,84)$} & \multicolumn{2}{|c|}{$50,86(7,03)$} \\
\hline Frekuensi kemoterapi & \multicolumn{2}{|c|}{$6,83(4,02)$} & \multicolumn{2}{|c|}{$7,57(5,15)$} \\
\hline
\end{tabular}

Tabel 2. Hasil Analisis Kualitas Tidur pada Kedua Kelompok

\begin{tabular}{lccc}
\hline \multicolumn{1}{c}{ Kelompok } & n & Rata-rata & $\begin{array}{c}\text { Nilai } \\
\mathbf{p}\end{array}$ \\
\hline Pretest & & & \\
Kontrol & 12 & 9,83 & \\
Intervensi & 14 & 12,93 & 0,017 \\
Posttest & & & \\
Kontrol & 12 & 11,83 & \\
Intervensi & 14 & 7,00 & 0,003 \\
\hline
\end{tabular}

intervensi dan 50\% ada kelompok kontrol. Pada lama kemoterapi kelompok intervensi 92,9\% dan kontrol $100 \%<1$ tahun. Penggunaan lampu pada saat tidur mayoritas menggunakan lampu saat tidur pada kelompok intervensi 57,1\% dan kontrol 75\%. Usia kelompok intervensi maupun kontrol merupakan lansia awal dengan kisaran pada kelompok intervensi 51 tahun dan kontrol 49 tahun, sedangkan pada frekuensi kemoterapi dengan rata-rata baik kelompok kontrol maupun intervensi sebanyak 7-8 kali.

Hasil analisis Independent sample t-test dapat dilihat pada Tabel 2. Tabel 2. menunjukkan bahwa hasil pretest pengukuran kualitas tidur pada kelompok inter-vensi dan kontrol mempunyai perbedaan dengan rata-rata pada kelompok kontrol 9,83 dan inter-vensi 12,93 dengan $p$ value $=0,017$. Hasil posttest ke-lompok kontrol 11,83 intervensi 7,00 dengan $p$ value=0,003. Tabel 2 . diketahui bahwa $p$ value $(p<0,05)$, sehingga dapat dikatakan bawa pada kelom-pok kontrol mengalami peningkatan nilai kualitas tidur menjadi lebih buruk dan pada kelompok inter-vensi terjadi penurunan nilai. Disimpulkan bahwa Penerapan sunnah Rosul sebelum tidur efektif un-tuk meningkatkan kualitas tidur pasien kanker pa-yudara yang menjalani kemoterapi.

\section{DISKUSI}

Karakteristik demografi. Semakin tinggi tingkat pendidikan seseorang maka semakin tinggi tingkat pengetahuannya. ${ }^{11}$ Pada penelitian tingkat pendidikan sebagian responden SD, sehingga untuk pengetahuan terkait pencegahan kanker maupun penanganan gangguan tidur sedikit.

Penatalaksanaan kanker menggunakan kemoterapi pada tahap awal menjalani kemoterapi menjadi faktor utama yang membuat kualitas tidur buruk atau mengalami gangguan tidur. ${ }^{5}$ Gangguan tidur yang terjadi akibat kemoterapi yaitu pada komponen latensi tidur dan terbangun pada malam hari. 
Kemoterapi menyebabkan seseorang membutuhkan 34,8 menit untuk mulai tertidur dan terbangun sebanyak 21-29 kali pada malam hari. ${ }^{12}$ Berbagai hal ini mengakibatkan singkatnya waktu yang dimiliki pasien untuk tidur dan membuat kualitas tidur pasien menjadi buruk. ${ }^{13}$

Penggunaan lampu yang redup atau mati saat tidur memberikan efek positif terhadap waktu terjaga atau kewaspadaannya menjadi lebih singkat, membuat lebih cepat mengantuk. ${ }^{14}$, 15 Seseorang yang terpapar cahaya durasi lama (4 dan 6,5 jam) di malam hari membuat tertundanya fase tidur. ${ }^{16}$

American Cancer Society yang menunjukkan bahwa angka kejadian kanker terbanyak pada usia 50-69 tahun, ${ }^{1}$ di Indonesia prevalensi kejadian kanker terbaru banyak pada usia 45-54 tahun. ${ }^{17}$ Hal ini sesuai dengan pendapat Nurzallah (2015), ${ }^{18}$ meningkatnya risiko terjadinya kanker payudara sejalan dengan bertambahnya usia.

Pada pasien yang menjalani kemoterapi untuk pertama kali maupun seterusnya tetap mengalami gangguan tidur akibat seringnya terbangun tengah malam untuk ke kamar mandi, gelisah atau tidak bisa untuk memulai tidur sebelum atau setelah terbangun pada tengah malamnya. ${ }^{19}$ Pasien yang telah berulang kali mendapatkan kemoterapi semakin berisiko mengalami gangguan tidur dan insomnia, sehingga perlu diberikan terapi untuk menangani gangguan tidurnya. ${ }^{5}$

Penerapan Sunnah Rosul sebelum tidur. Hasil penelitian George et al. (2016), ${ }^{13}$ nilai penilaian kualitas tidur menggunakan PSQI 7,6 $\pm 4,0$ yang menunjukkan bahwa pasien memiliki kualitas tidur buruk. Hasil yang sama didapatkan oleh Yennursjslingsm et al. (2015), ${ }^{20}$ hasil pengukuran kualitas tidur pada pasien kanker dengan kemoterapi 8,0 $\pm 3,7$ di University Texsas MD Anderson Cancer Center yang dilakukan pada 180 seluruh pasien kanker. Dapat dikatakan baik dalam penelitian ini maupun penelitian sebelumnya yang melihat kualitas tidur pasien kanker payudara yang menjalani kemoterapi yang diukur dengan kuesioner yang sama mendepatkan nilai kualitas tidur yang buruk lebih dari 5 .

Pemberian intervensi untuk penatalaksanaan gangguan tidur menggunakan musik efektif dapat meningkatkan kualitas tidur, musik didengarkan selama 20-30 menit dengan 10 kali sesi pertemuan. ${ }^{21}$ Selain itu pasien-pasien yang diberikan penatalaksanaan gangguan tidur mendengarkan murottal AlQur'an efektif meningkatkan kualitas tidur. Murottal Al-Qur'an diberikan selama 15 menit dalam 7 ha- ri. ${ }^{22}$ Melakukan dzikir efektif untuk meningkatkan kualitas tidur yang dilakukan selama 10-15 menit.9,23

Pasien yang diberikan penatalaksanaan untuk mengurangi gangguan tidurnya akan meningkatkan kualitas tidur semakin membaik, sedangkan yang tidak diberikan penatalksanaan kualitas tidurnya semakin buruk dengan hasil pada kelompok kontrol pretest 16,40 dan posttest $16,80,{ }^{24}$ atau nilai kualitas tidur tidak mengalami penurunan yang signifikan pretest 6,001 dan posttest $5,842 .{ }^{23}$

Intervensi pemberian terapi murottal merupakan salah satu terapi musik yang memiliki pengaruh positif bagi pendengaran..$^{25}$ Terapi musik efektif untuk meningkatkan kualitas tidur pada pasien kemoterapi dan radioterapi. ${ }^{21}$ Murottal merupakan salah satu terapi musik yang memeiliki pengaruh positif bagi pendengaran. ${ }^{26}$

Terapi murottal Al-Qur'an dengan tempo yang lambat serta harmonis dapat menurunkan hormonhormon stres, mengaktifkan hormon endorfin alami (serotonin). Mekanisme ini dapat memperbaiki sistem kimia tubuh sehingga menurunkan tekanan darah, memperlambat pernafasan, detak jantung, denyut nadi dan aktivitas gelombang otak, ${ }^{27,28}$ dan dapat meningkatkan perasaan rileks atau nyaman, mengalihkan perhatian dari rasa takut atau kecemasan, ${ }^{28}$ meningkatkan kualitas tidur. ${ }^{12,28,29,30}$

Melakukan dzikir mengeluarkan hormon beta endorphin yang membuat pelakunya menjadi rileks dan mendapatkan kebahagiaan, ${ }^{28}$ selain itu melakukan kegiatan sunnah Rosul sebelum tidur dapat meningkatkan kualitas tidur. ${ }^{9}$

IImu kedokteran telah banyak mengungkapkan manfaat dari metode Al-Qur'an sebagai pengobatan kuratif. Di dalam kitab suci Al-Qur'an surat QS. Ar-Ra'd, menyatakan Al-Qur'an diturunkan sebagai penyembuh dan petunjuk bagi orang-oarang yang beriman "Yaitu orang-orang yang beriman dan hati mereka menjadi tentram dengan mengingat Allah. Ingatlah, hanya dengan mengingat Allah-lah hati menjadi tentram." (QS. Ar-Ra'd, 13:28). ${ }^{31}$

Melakukan penerapan sunnah Rosul sebelum tidur, dapat memberikan efek positif bagi tubuh. ${ }^{30}$ Saat mengamalkan kegiatan sunnah Rosul Muhammad SAW, maka yang mengamalkannya akan mendapatkan banyak manfaat selain dari pahala yaitu tidur menjadi lebih optimal. ${ }^{32}$ Disimpulkan penerapan sunnah Rosul sebelum tidur efektif untuk mengatasi keluhan gangguan tidur yang dialami pasien kanker payudara yang menjalani kemoterapi. 


\section{SIMPULAN}

Terdapat peningkatan kualitas tidur pasien kanker payudara yang menjalani kemoterapi setelah diberikan intervensi penerapan sunnah Rosul sebelum tidur.

\section{DAFTAR PUSTAKA}

1. American Cancer Society. Cancer facts $\mathscr{E}$ figures. The Society. 2017. Diakses dari https://www.cancer.org/content/dam/cancerorg/research/cancer-facts-and-statistics/breastcancer-facts-and-figures/breast-cancer-facts-andfigures-2017-2018.pdf. Diakses pada Oktober 2017.

2. Charalambous A, Kaite CP, Charalambous M, Tistsi T, Kouta C. The Effects on Anxiety and Quality of Life of Breast Cancer Patients Following Completion of the First Cycle of Chemotherapy. SAGE open med, 2017; 5.

3. Zhang J, Zhou Y, Feng Z, Xu Y, Zeng G. Longitudinal Trends in Anxiety, Depression and Quality of Life during Different Intermittent Periods of Adjuvant Breast Cancer Chemotherapy. Cancer nursing, 2018; 41 (1): 62-68.

4. Garland SN, Johnson JA, Savard J, Gehrman P, Perlis M, Carlson L, Campbell T. Sleeping Well With Cancer: A Systematic Review of Cognitive Behavioral Therapy for Insomnia in Cancer Patients. Neuropsychiatr dis treat, 2014; 10: 1113-24.

5. Tian J, Chen GL, Zhang HR. Sleep Status of Cervical Cancer Patients and Predictors of Poor Sleep Quality during Adjuvant Therapy. Support Care Cancer, 2015; 23 (5): 1401-1408.

6. Budhrani PH, Lengacher CA, Kip K, Tofthagen C, Jim H. An Integrative Review of Subjective and Objective Measures of Sleep Disturbances in Breast Cancer Survivors. Clin J Oncol Nurs, 2015; 19 (2): 185-191.

7. Lafçi D, \& Öztunç G. The Effect of Music on the Sleep Quality of Breast Cancer Patients. Int J Caring Sci, 2015; 8 (3): 633-640.

8. Ong JC, Manber R, Segal Z, Xia Y, Shapiro S, Wyatt JK. A Randomized Controlled Trial of Mindfulness Meditation for Chronic Insomnia. Sleep, 2014; 37 (9): 1553-1563.

9. Al-Halaj QMI. Pengaruh Dzikir Menjelang Tidur terhadap Kualitas Tidur Lanjut Usia di Panti Sosial Tresna Wredha Budi Mulia 01 Jakarta Timur. Skripsi. UIN Syarif Hidayatullah Jakarta. 2015. Diakses dari

http://repository.uinjkt.ac.id/dspace/bitstream/12 3456789/25630/1/Qoys\%20Muhammad\%20Iqba
1\%20Al-Halaj\%20-\%20fkik.pdf. Diakses pada Oktober 2017.

10. Buysse DJ, Reynolds CF, Monk TH, Berman SR, Kupfer DJ. The Pittsburgh Sleep Quality Index: A New Instrument for Psychiatric Practice and Research. Psychiatry Res, 1989; 28 (2): 193-213.

11. Notoatmodjo S. Ilmu Perilaku Kesehatan. Jakarta: Rineka Cipta. 2014.

12. Kurniyawan EH. Murottal Al-Quran Therapy to Increase Sleep Quality in Nursing Students. UNEJ e-Proceeding, 2018: 7-14.

13. George GC, Iwuanyanwu EC, Anderson KO, Yusuf A, Zinner RG, Piha- Paul SA, et al. Sleep Quality and its Association with Fatigue, Symptom Burden and Mood in Patients with Advanced Cancer in a Clinic for Early- Phase Oncology Clinical Trials. Cancer, 2016; 122 (21): 3401-3409.

14. Chang AM, Santhi N, St Hilaire M, Gronfier C, Bradstreet DS, Duffy JF, et al. Human Responses to Bright Light of Different Durations. J Physiol, 2012; 590 (13): 3103-3112.

15. Cho Y, Ryu SH, Lee BR, Kim KH, Lee E, Choi J. Effects of Artificial Light at Night on Human Health: A Literature Review of Observational and Experimental Studies Applied to Exposure Assessment. Chronobiol Int, 215; 32 (9), 1294-1310.

16. Zeitzer JM, Ruby NF, Fisicaro RA, Heller HC. Response of the Human Circadian System to Millisecond Flashes of Light. PloS one, 2011; 6 (7): e22078.

17. Riset Kesehatan Dasar (Riskesdas). Badan Penelitian dan Pengembangan Kesehatan Kementerian RI Tahun 2013. 2013.Diakses dari http://www.depkes.go.id/resources/download/gen eral/Hasil\%20Riskesdas\%20 2013.pdf. diakses pada Oktober 2017.

18. Nurzallah PA. Pengaruh Pemberian Terapi Musik Klasik Mozart terhadap Waktu Pulih Sadar Pasien Kanker Payudara dengan Anestesi General di RSUD Dr. Moewardi Surakarta. Skripsi. Universitas Muhammadiyah Surakarta. 2015.

19. Davis MP, Goforth HW. Long-Term and ShortTerm Effects of Insomnia in Cancer and Effective Interventions. Cancer J, 2014; 20 (5): 330-344.

20. Yennurajalingam S, Balachandran D, Cardozo SLP, Berg EA, Chisholm GB, Reddy A, et al. PatientReported Sleep Disturbance in Advanced Cancer: Frequency, Predictors and Screening Performance of the Edmonton Symptom Assessment System Sleep Item. BMJ Support Palliat Care, 2017; 7 (3): 274-280.

21. Vinayak S, Dehkhoda F, Vinayak R. The Effect of Music Therapy on Sleep Quality of Cancer Patients 
Undergoing Chemotherapy or Radiotherapy: A Randomized Control Trial. J Social Sci, 2017; 6 (4): 734-743.

22. Oktora SPD, Purnawan I, Achiriyati D. Pengaruh Terapi Murottal Al Qur'an terhadap Kualitas Tidur Lansia di Unit Rehabilitasi Sosial Dewanata Cilacap. Jurnal Keperawatan Soedirman (The Soedirman Journal of Nursing), 2016; 11 (3): 168-173.

23. Reflio R, Dewi AP, Utomo W. Pengaruh Terapi Al Zikir terhadap Kualitas Tidur Lansia. Jurnal Online Mahasiswa Program Studi Ilmu Keperawatan Universitas Riau, 2016; 2 (2): 1418-1425.

24. Suryani S, Salmiyati S. Pengaruh Terapi Audio Murottal Surah Ar-Rahman terhadap Tingkat Insomnia pada Lanjut Usia di UPT Panti Wredha Budhi Dharma Ponggalan Yogyakarta. Doctoral dissertation, Universitas' Aisyiyah Yogyakarta. 2017.

25. Li XM, Zhou KN, Yan H, Wang DL, Zhang YP. Effects of Music Therapy on Anxiety of Patients with Breast Cancer after Radical Mastectomy: A Randomized Clinical Trial. J Adv Nurs, 2012; 68 (5): 1145-1155.
26. Bunt L, Stige B. Music Therapy: An Art Beyond Words (2nd ed). London: Routledge. 2014.

27. Altenmüller E, Schlaug G. Music, Brain and Health: Exploring Biological Foundations of Music's Health Effects. Music, health, and wellbeing, 2012.p.12-24.

28. Haruyama S. The Miracle of Endhorphin. Bandung: Mizan Pustaka. 2013.

29. Maghfirah N. 99 Fenomena Menakjubkan dalam AlQuran. Jakarta: Mizania. 2015.

30. Hananta L, Benita S, Barus J, Halim F. Gangguan Tidur pada Pasien Kanker Payudara di Rumah Sakit Dharmais Jakarta. Damianus J Med, 2014; 13 (2): 84-94.

31. Qomari. Departement Agama Republik Indonesia Alqur'an dan Terjemahan 30 juz. Solo: PT Qomari Prima Publisher. 2007.

32. Irham MI. Panduan Meraih Kebahagiaan Menurut AlQur'an. Jakarta: Penerbit Hikmah. 2011. 